\title{
Soda Lime Silicate Glass-Copper Metal Joining by Controlled Heat Treatments in Air
}

\author{
M.B. TELLi* \\ Kocaeli University, Metallurgical and Materials Engineering Department, Engineering Faculty Building, \\ 41380 Izmit, Kocaeli, Turkey
}

\begin{abstract}
Metal-glass joints are needed to improve efficiencies of heat collecting units used in linear parabolic sun collector systems. Soda lime silicate glass-copper metal joints were prepared at $800{ }^{\circ} \mathrm{C}$ for 5,10 and 20 min by furnace treatment in air. $\mathrm{Cu}$ is rapidly oxidized with heat treatment in air, reacted with glass and formed some bubbles at reaction interface. Scanning electron microscope investigation suggested copper oxide formation at copper interface, reaction between copper oxide and glass and formation of bubbles at joining interface and some microcracking for the studied glass disk on Cu disk sample profiles. ANSYS14 software simulations suggested joined glass experienced complicated and high residual stress levels due to big thermal expansion coefficient difference and bubble formation at the joining interface. The residual minimal principal stress levels were at the order of $-400 \mathrm{MPa}$ for joined glass at interface produced microcracking in glass starting from joined interface growing into glass layer.
\end{abstract}

DOI: 10.12693/APhysPolA.129.482

PACS/topics: $81.20 . \mathrm{Vj}$

\section{Introduction}

Borosilicate glass - Kovar alloy joining is generally preferred for this application due to their closely matched thermal expansion coefficients [2]. Soda lime silicate glass is one of the economically available glasses and often used for outdoor applications [3]. Copper tubing is easily accessible and mainly used in plumbing and heating applications due to its good corrosion resistance [4]. In addition, copper is reported to be one of metals used for joining with glasses having high temperature coefficient of expansion [5]. If soda lime silicate glass-copper joining is achieved, it could be an economical alternative for heat collecting unit applications. However, there are not many studies reporting details of soda lime silicate glass to copper by heat treating in air. This study investigates effects of heat treatment in air on soda lime silicate glass-copper joining interfaces, provides finite element method analysis of maximal and minimal principal residual stresses that glass-copper joining interface experiences for studied sample profile and concludes with critical points for joining soda lime silicate glass-copper joining.

\section{Experimental procedure}

Soda lime silicate glass (Schott Ar glass, Germany) and commercially pure (99.9 wt\%) copper rods were used in the experiments. Soda lime silicate glass disk (having $10 \mathrm{~mm}$ diameter and $2 \mathrm{~mm}$ height) on $\mathrm{Cu}$ disk (having $12 \mathrm{~mm}$ diameter and $1.4 \mathrm{~mm}$ height) samples were prepared by employing a diamond saw and grinding with a 1000 grade $\mathrm{SiC}$. Samples were inserted directly into preheated furnace at $800{ }^{\circ} \mathrm{C}$ and heat treated in air for time durations of 5,10 , and $20 \mathrm{~min}$, thermally annealed at $550{ }^{\circ} \mathrm{C}$ for $20 \mathrm{~min}$ for removing any joining stress developed in glass due to prior higher temperature bonding step and cool down to $550^{\circ} \mathrm{C}$ and finally cooled down to room temperature for $3 \mathrm{~h}$ in furnace.

Scanning electron microscope (SEM) investigations were done by employing JEOL 6060 model scanning electron microscope with energy dispersive spectrometer (EDS) and with Au sputtering. Finite element modeling and analysis of joining residual maximal and minimal principal stresses for the used disc on disc sample were done employing ANSYS 14 software and assuming linear elastic material behaviour. Table I provides used material properties in the models. Calculations were done for disc on disc sample with a formed bubble having semispherical shape with a radius of $0.5 \mathrm{~mm}$ and residual stresses developed due to cooling down of bonded glasscopper joints from thermal stress relieving annealing step at $550{ }^{\circ} \mathrm{C}$ to room temperature.

TABLE I

Materials properties used for residual joining stress calculations $[6,7]$.

\begin{tabular}{c|c|c}
\hline \hline $\begin{array}{c}\text { Materials } \\
\text { Property }\end{array}$ & $\begin{array}{c}\text { Soda Lime } \\
\text { Silicate Glass }\end{array}$ & $\mathrm{Cu}$ \\
\hline thermal expansion & $9.1 \times 10^{-6}$ & $20.2 \times 10^{-6}$ \\
coefficient $(\alpha)$ & & $110 \times 10^{9}$ \\
Young modulus $(E)[\mathrm{Pa}]$ & $73 \times 10^{9}$ & 0.364 \\
Poisson ratio $(v)$ & 0.22 &
\end{tabular}




\section{Results and discussion}

Figure 1 shows that soda lime silicate glass bonded well to copper without showing any sign of extensive macro cracking with an air heat treatment at $800^{\circ} \mathrm{C}$. However, bubble formation at glass layer close to joining interface was observed. In Fig. 1a bubble formation was minimal for the sample joined at $800^{\circ} \mathrm{C}$ in air for $5 \mathrm{~min}$. Increase in heat treatment duration lead to increase in buble formation as seen in Fig. 1b and c more clearly.
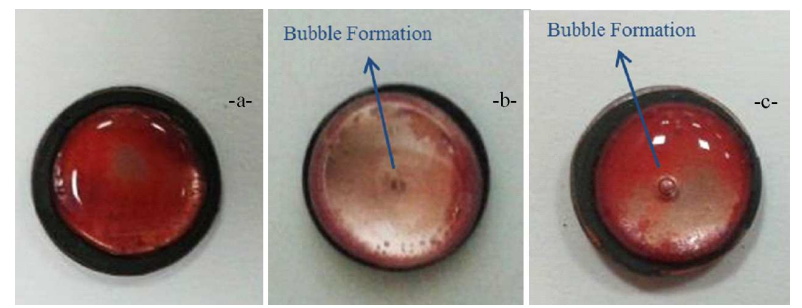

Fig. 1. Soda lime silicate glass disc on $\mathrm{Cu}$ disc samples joined at $800^{\circ} \mathrm{C}$ in air for heat treatment durations of (a) 5, (b) 10 and (c) $20 \mathrm{~min}$.

Figure 2a illustrates cracking in glass layer at $30 \times$ magnification secondary electron SEM image and part (b) shows bubble formation in glass layer at $\mathrm{CuO}$ interface at $1000 \times$ magnification image. Observed cracking in glass layer suggested that residual joining stress levels were high for the used joining sample dimensions. Bubble formation at soda lime silicate glass and oxidized copper layer interface suggested that due to chemical reaction between glass and copper oxide.
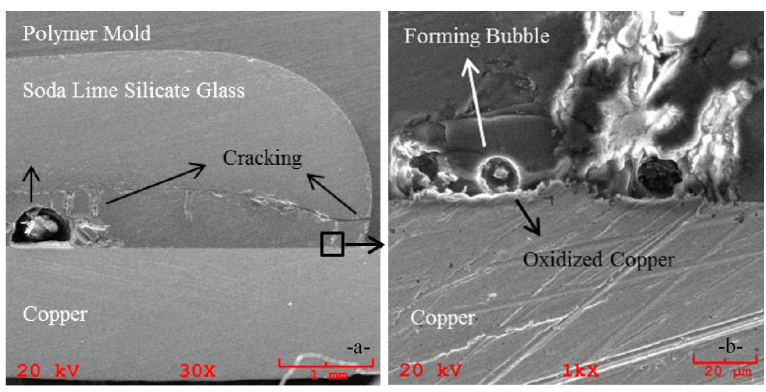

Fig. 2. Scanning electron microscope images of $5 \mathrm{~min}$ $800{ }^{\circ} \mathrm{C}$ heat treated sample: (a) $30 \times$ magnification of cross-sectional sample, (b) $1000 \times$ magnification image of showing bubble formation.

Figure 3a shows the heat treatment in air for $5 \mathrm{~min}$ at $800^{\circ} \mathrm{C}$ leads to oxidation of copper surface and some chemical reaction between oxidized copper with soda lime silicate glass. While spot EDS analysis 1 (Fig. 3b) suggested oxidized copper layer made up of only $\mathrm{Cu}$ and $\mathrm{O}$ atoms, spot EDS analysis 2 (Fig. 3c) revealed that some $\mathrm{Cu}$ diffusion towards soda lime silicate glass interior occurred due to reaction between copper oxide layer and glass. Therefore, bubble formation was thought to be as a result of interfacial reaction leading copper diffusion from copper oxide layer into glass and leaving unreacted $\mathrm{O}$ to form $\mathrm{O}_{2}$ gas bubbles at joining interface.
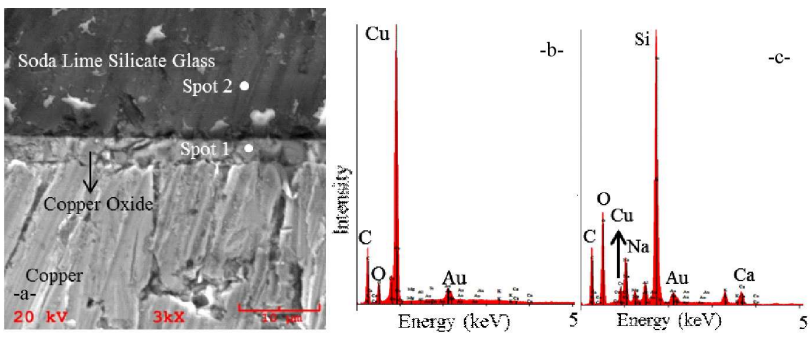

Fig. 3. Scanning electron microscope image and spot EDS analysis of $5 \mathrm{~min} 800^{\circ} \mathrm{C}$ heat treated sample: (a) copper-glass interface at $3000 \times$ magnification, (b) EDS analysis taken from copper oxide layer at spot position 1, (c) EDS analysis taken from copper oxide layer at spot position 2 .

Figure 4 suggested that both $\mathrm{Cu}$ and soda lime silicate glass experienced rather high residual stress levels at joining interface for used sample profiles. While $\mathrm{Cu}$ layer had highest maximal principal stress levels at the order of $450 \mathrm{MPa}$ at joining interface close to formed bubble as seen in Fig. 4a, soda lime silicate glass had highest minimal principal stress levels at the order of $-400 \mathrm{MPa}$ at towards circumference of glass bonded to copper joining interface and around formed bubble as seen in Fig. $4 \mathrm{~b}$. In addition, bubble formation at glass-copper joining interface was found to be complicating and increasing minimal principal stress that glass experienced near joining interface.

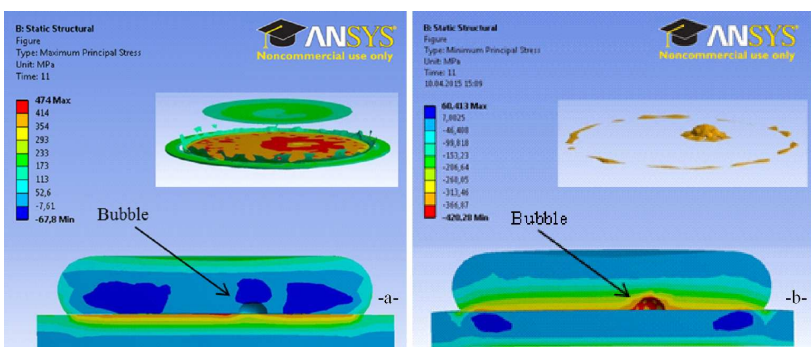

Fig. 4. ANSYS 14 simulation results of residual joining stress levels: (a) maximal principal stress levels of cross section region having bubble and inset showing stress levels higher than $150 \mathrm{MPa}$, (b) minimal principal stress of cross section region having bubble and inset showing regions having stress levels lower than $-350 \mathrm{MPa}$.

Observed high residual stresses levels leading to glass cracking were mainly due to big thermal expansion differences between soda lime silicate glass (TCE of $9.1 \times 10^{-6}$ ) and copper (TCE of $20.2 \times 10^{-6}$ ). To prevent cracking of glass, residual stress levels need to be lowered. Use of an intermediate layer between glass and copper having intermediate thermal expansion coefficient could lower residual stresses on glass and prevent observed cracking in glass layer. 


\section{Conclusion}

Soda lime silicate glass-copper joining in air with a heat treatment at $800^{\circ} \mathrm{C}$ lead copper oxidation and reaction of formed copper oxide with soda lime silicate glass resulted in bubble formation at joining interface. Due to thermal expansion coefficient difference, high maximal principal stress levels at copper layer and high minimal principal stress levels at that glass at interface were observed for disc on disc sample profiles. While $\mathrm{Cu}$ layer had highest maximal principal stress levels at the order of $450 \mathrm{MPa}$ at joining interface and soda lime silicate glass had lowest minimal principal stress levels at the order of $-400 \mathrm{MPa}$ around formed big bubble at interface and around close to outer joining circumference. Observed cracking in glass was consistent with residual stress calculations around formed big bubble and interfacial cracks starting from joining interface close to glass outer section close to circumference. For successful copper soda lime silicate glass-copper joining, residual stress levels and bubble formation due to reaction between oxidized copper and soda lime silicate glass needs to be minimized.

\section{Acknowledgments}

This study was financially supported by scientific research project 2011-70 of Kocaeli University, Turkey.

\section{References}

[1] D. Lei, Z. Wang, J. Li, Mater. Des. 31, 1813 (2010).

[2] C. Chanmuang, M. Naksata, H. Jain, C.E. Lyman, Mater. Sci. Eng. A 474, 218 (2008).

[3] J.E. Shelby, Introduction to Glass Science and Technology, 2nd ed., The Royal Society of Chemistry, Cambridge UK 2005.

[4] J.R. Davis, Copper and Copper Alloys, ASM Specialty Handbook, ASM International, Materials Park, OH 2001

[5] R.W. Messler, Joining of Materials and Structure: From Pragmatic Process to Enabling Technology, Elsevier, Burlington 2004.

[6] "Schott tubing brochure for Ar-glass", www.schott. $\mathrm{com} /$.

[7] "Pure cold drawn Cu properties", www.matweb.com/. 